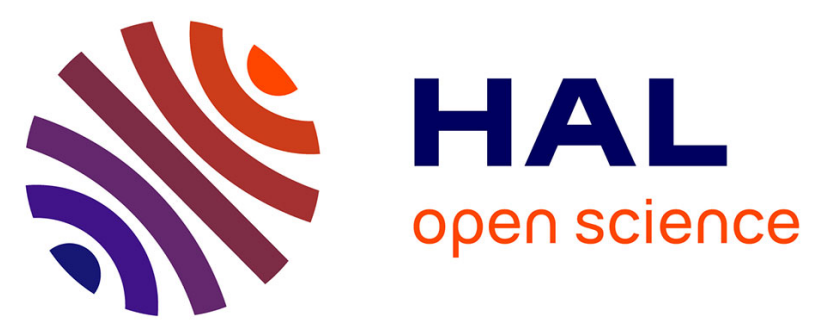

\title{
Designing and Evaluating a Workstation in Real and Virtual Environment: Toward Virtual Reality Based Ergonomic Design Sessions
}

Charles Pontonnier, Georges Dumont, Afshin Samani, Pascal Madeleine, Marwan Badawi

\section{To cite this version:}

Charles Pontonnier, Georges Dumont, Afshin Samani, Pascal Madeleine, Marwan Badawi. Designing and Evaluating a Workstation in Real and Virtual Environment: Toward Virtual Reality Based Ergonomic Design Sessions. Journal on Multimodal User Interfaces, 2013, pp.1-10. 10.1007/s12193013-0138-8 . hal-00908149

\section{HAL Id: hal-00908149 \\ https://hal.science/hal-00908149}

Submitted on 13 Dec 2013

HAL is a multi-disciplinary open access archive for the deposit and dissemination of scientific research documents, whether they are published or not. The documents may come from teaching and research institutions in France or abroad, or from public or private research centers.
L'archive ouverte pluridisciplinaire HAL, est destinée au dépôt et à la diffusion de documents scientifiques de niveau recherche, publiés ou non, émanant des établissements d'enseignement et de recherche français ou étrangers, des laboratoires publics ou privés. 


\title{
Designing and Evaluating a Workstation in Real and Virtual Environment: Toward Virtual Reality Based Ergonomic Design Sessions
}

Author version, published in journal on multimodal user interfaces

\begin{tabular}{|c|c|}
\hline Charles Pontonnier & Georges Dumont \\
Ecoles de Saint-Cyr Coëtquidan & Ens Cachan Antenne de Bretagne \\
IRISA-INRIA Rennes & IRISA-INRIA Rennes \\
Campus de Beaulieu & Campus de Beaulieu \\
35042 Rennes Cédex, France & 35042 Rennes Cédex, France \\
Tel.: +33-2-99842509 & Tel.: +33-2-99842574 \\
Fax: +33-2-99847171 & Fax: +33-2-99847171 \\
E-mail: charles.pontonnier@irisa.fr & E-mail: georges.dumont@irisa.fr \\
\hline Afshin Samani & \\
Department of Health Science and Technology & Pascal Madeleine \\
Aalborg University & Department of Health Science and Technology \\
Fredrik Bajers Vej 7 D-3 & Aalborg University \\
9220 Aalborg, Denmark & Fredrik Bajers Vej 7 D-3 \\
Tel. : +45-99402411 & 9220 Aalborg, Denmark \\
Fax +45-98154008 & Tel. : +45-99408833 \\
E-mail: afsamani@hst.aau.dk & Fax +45-98154008 \\
Marwan Badawi & E-mail: pm@ hst.aau.dk \\
IRISA-INRIA Rennes & \\
Campus de Beaulieu & \\
35042 Rennes Cédex, France & \\
Tel.: +33-2-99847127 & \\
Fax: +33-2-99847171 & \\
E-mail: marwan.badawi@irisa.fr & \\
\hline
\end{tabular}

\begin{abstract}
This paper adresses the issue of properly designing a digital mockup (DMU) to be used in an experiment comparing simulated assembly tasks in both real and virtual environments. Motivations and specifications relative to the experiment are reported, and the design process of the DMU is described and illustrated. Recommendations are proposed with a particular focus on specificities relative to the use of a DMU as a support for both manufacturing and virtual reality - 3D visualisation and interaction. A subjective evaluation of Real (RE), Virtual (VE), and Virtual with Force Feedback (VEF) environments is provided. Results indicate a real sensory and difficulty gap between RE and VEF, whereas a smaller difference was observed between RE and VE. In further improvements of scale-1 (where the objects in VE have the same size as in the real environment), colocalized simulation using haptic devices are warranted to fill in this gap. Results also highlight the impact of cognition and sensory feedback on user's feeling and presence sensation. Applications of such numerical designs are presented in the last section, especially focusing on collaborative design sessions. Virtual Reality based evaluation of newly designed workstations will be a way in the future to improve design and user learning processes.
\end{abstract}

Keywords fidelity sensor-bridging sensor-sharing virtual reality interaction 


\section{Introduction}

The use of Virtual Reality (VR) as a support for products [40] or workstations design [8,14] tends to be generalized in the near future. Indeed, virtual prototyping - the act of evaluating a product by simulating its behavior and its interactions with humans and/or other components has become increasingly relevant, especially for evaluating assembly tasks. At this point, the use of such tools becomes quite natural to evaluate the functionalities or ergonomic features of workstations [2,41] since it is more cost-effective and easier to edit a digital mock-up (DMU) than a real mock-up.

In order to evaluate ergonomic features, the user is immersed in a Virtual Environment (VE) mimicking the Real Environment (RE), and reproduces a more or less realistic metaphor of the real task. Motion capture, electromyographic (EMG) electrodes, force sensors, and subjective indicators provide an evaluation of sensory and motor aspects such as muscle fatigue and discomfort $[23,25,26,30]$. In the near future, one can expect to obtain a VRbased simulator allowing a remote intervention of ergonomists on a digital mock-up and on the worker's gestures to minimize muscle fatigue and avoid potential risks ofWork Related Musculoskeletal Disorder (WMSD) appearance.

Since VE do not perfectly mimic reality in terms of visualization, simulation, and interaction, a work task performed in VE differs deeply from a one performed in RE in terms of cognition, sensory feedback, and motor control [34]. Moreover, unfamiliar environments tend to affect the way we perform what we consider as well-known tasks [19]. To reduce the gap between RE and VE it is necessary to prepare the DMU with caution, as it will be used as a VE and manufactured at the same time. On one hand, the DMU has to reach a compromise between performance and fidelity to be used as a VE. On the other hand, it has to ensure functionalities and specificities mandatory to its fabrication.

Within the framework of the VISIONAIR project [16], the Trans-National Access project VR-GO proposed by the Center for Sensory-Motor Interaction (SMI) in Aalborg (Denmark) took place in the IMMERSIA room, Rennes (France). The goals were to perform manual handling tasks in both RE and VE, using subjective and objective indicators to quantify discrepancies in terms of e.g. discomfort and fatigue experience. The project aimed at answering the following question: How does a virtual environment interfere with motion pattern and muscular activation? Assessing objective and subjective fidelity of simulated assembly tasks in VE with regard to RE is crucial when seeking knowledge on how ergonomics can be evaluated in a virtual framework.

This article presents the design process of a DMU for of simulated assembly tasks and an initial evaluation of the experimental protocol, focusing on the specificities of the numerical pipeline used to design the DMU. A subjective evaluation of fidelity is presented in order to understand the perception of VE and VEF with regard to RE. A first part relative to the virtual prototyping of assembly tasks introduces the main motivations and specifications relative to the current study. Then the motivations and specifications of the current DMU design and the implementation and the realization of the mock-up are presented. A subjective evaluation of fidelity and the associated results are presented and discussed and a final section aims at presenting the applications of such a VR-based simulator, especially for collaborative ergonomics design sessions.

Pontonnier et al. 


\section{Virtual prototyping in ergonomics of assembly processes}

Virtual prototyping has been widely adopted as a design and validation practice in several industrial sectors and, for a long time companies have been moving from expensive physical prototypes to the more convenient use of digital mock-ups. For example, Boeing [32], Volkswagen [7], Caterpillar [21] or General Motors [15] have all been evaluating the benefits of VR technology to reduce the number of physical prototypes by using simulations implemented on digital mock-ups in a virtual environment.

Virtual prototyping of assembly tasks has been massively studied because the assembly process represents a significant part of the cost of a product [4]. Commercial CAD softwares can be used in assembly process planning by manually selecting the mating surfaces, axes and/or edges to assemble the parts. Nevertheless these interfaces do not reflect human interaction with complex parts, especially the accurate manipulation of the parts and the global attitude of the human during the task. Such computer-based systems are unable to address issues related to ergonomics of the task, e.g. to detect awkward postures or peaks of muscular activity during assembly operations. This is the reason why haptics saw an outstanding development in the past few years. In using haptics technology, engineers can touch and feel complex CAD models and interact with them using natural and intuitive human motions [38]. Moreover, collision and contact forces, computed in real-time, can be transmitted to the operator as a force feedback. Therefore, the operator experiences the physical contacts computed by the simulation during the assembly task. In [33], the authors proposed a physically-based modeling tool for simulating realistic part-to-part and hand-topart interactions through a dual handed haptic interface. A method is proposed in [36] for interactive assembly operations by applying both kinematic constraints and guiding virtual fixtures. The purpose of this method is to help the user to perform the assembly task and to ensure a good assembly of CAD objects in disabling most of the physical interactions during the assembly task. From an assessment point of view, a quantitative analysis concerning the significance of haptic interactions in performing simulations of manual assemblies was performed in [30, 37].

The second main field of application for virtual prototyping is closely linked to the first one and concerns ergonomics. Studies in ergonomics can be separated into two categories [24]: the first one concerns the user's point of view and his ability to use a product. The second one concerns the worker's point of view and his capacity to perform, without additional risks, the assembly of the product as well as the tasks associated to his workstation. This has been studied from a cognitive point of view with a focus on the importance of human input to the design process $[6,13]$. The interest of using haptics for ergonomic evaluations of assembly tasks has been demonstrated in $[5,39]$ to have the potential to significantly increase both speed and accuracy of human-computer interactions. It has also been shown that the virtual prototyping could be used to minimize the physical risks factors involved in the musculoskeletal disorders appearance [30].

In this paper, we focus on the efficient design and evaluation of a digital mockup used to perform an ergonomic intervention on a simulated assembly task in a virtual environment.

Pontonnier et al. 


\section{Motivations and specifications}

The definition of the experiment relied on two main points. The specifications partially came from the goal to perform ergonomic studies and partially from technical purposes driven by the ability to efficiently build the real setup and to use a 3D model of this setup within a virtual environment.

On the ergonomics evaluation side, the chosen assembly task had to involve elementary operations such as object manipulation, object sorting or target reaching under condition of repetitive movements in a standing posture. As the task can be performed by people of different morphology and size, the design of both real and virtual setups had to be flexible in terms of geometry definition and accessibility parameters. The environments and interaction types, i.e. real, virtual, and virtual plus force feedback, has been chosen to test different multimodal interactions. Therefore the experiment has been designed to provide an evaluation of the usability of these interaction types and environments to perform ergonomic design sessions. Namely, the final experiment aims at evaluating the relevance of the addition of haptic sense to enhance the system fidelity. Fidelity can be defined as the objective degree of exactness with which real-world experiences and effects are reproduced by a computing system [12].

On the technical side, the motion tracking of user's upper body had to be recorded synchronously with electromyography signals representing muscle activation. The switch between the three different types of interaction that are task in real environment (RE), task in virtual environment (VE) and task in virtual environment with force feedback (VEF) had to be done easily on a unique physical platform. Therefore the DMU had to be as flexible as possible to be manufactured and used both as a visually and interactively realistic virtual environment.

To meet these specifications, the following experiment was defined: the environment comprised a work bench including a storage $\mathrm{A}$ and a disposal zone $\mathrm{B}$, a holed box and twelve wooden objects. The holed box was located on a work plan $\mathrm{W}$ set at the elbow height as recommended for light work [18,29]. The storage and disposal zones were located $40 \mathrm{~cm}$ above the work plane and $16 \mathrm{~cm}$ left and $16 \mathrm{~cm}$ right of the holed box center respectively. The holed box had different holes with different cross-sectional contours. This allowed some of the objects ("fitters") to pass through, while others ("non-fitters") were blocked. During a trial, the subject stood in front of the workstation and after receiving a verbal let-go signal, took an object from the storage zone with his right hand. The subject had to pass fitters through a proper hole in the holed box while placing non-fitters in the disposal zone. There were six fitters and six non-fitters for each trial either in RE, VE or VEF. Tasks have been designed as simplified assembly tasks, including several elementary operations and conditions: target reaching, object manipulation, piece sorting, standing posture and repetitive motion. These specific features are well-known to be involved in WMSD appearance [10]. The dimensions of the workstation were defined in relation with the capacities of the interaction devices, especially the haptic device, to enable a scale-1 manipulation of the object.

Within-subject conditions were also mandatory to understand how differently they influenced the way the task was performed in RE and VE. These within-subject conditions were the timing regime and the complexity of the task. Timing regime had two different levels: "as fast as possible" and "time managed", complexity also had two different levels defined by the number of holes in the holed box: "2 holes" and "6 holes". 
Fig. 1 summarizes the specifications defined prior to the experiment design. An "idea map" was used to enhance the communication between ergonomists and computer scientists, and to help the proper design in considering both ergonomics and technical specifications. The map exhibits several level of details and summarizes the main characteristics of the experiment (biomechanical quantities recorded, whithin-subject factors and interaction types tested, ...). A similar idea map was initially used to define the mock-up specifications (type of material, dimensions in relation with the interaction device capacities and morphological data).

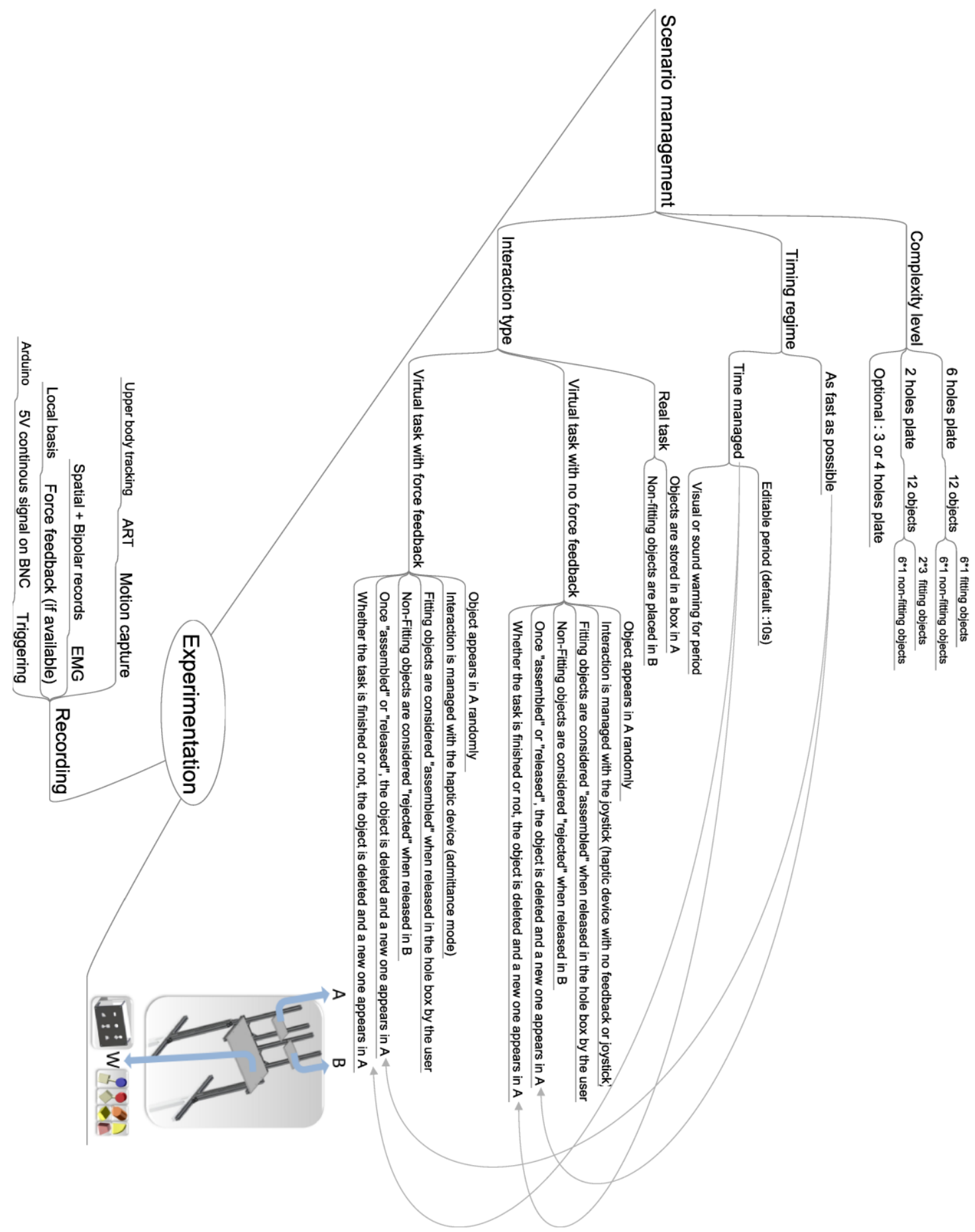

Fig. 1 Experiment design and specifications. 


\section{A DMU for designing RE, VE and VEF}

This section deals with the design of a flexible, exportable and manufacturable DMU and its implementation within the frame of the experiment described in the previous section. The complete design pipeline is shown in Fig. 2. As the task in the virtual environment has to be as faithful as possible to the one in the real environment, we used the same DMU for both spaces. On Fig. 2 top, views of the three main parts that were used during the experiment are presented:

- the work plan;

- the holed box;

- the different shapes including "fitters" and "non-fitters": these shapes were directly issued from a children holed box game.

In the same figure (second box), the data is exported for the manufacturing part. Using the same DMU of the setup, simplified representations are exported that lead to a visual representation for VR and a physical representation on which the physics simulator relies.

\subsection{Digital Mock-Up}

The DMU needed to be flexible, in the sense that the workstation needed to be adaptable to each subject with respect to the task specifications. The height of the shelves had to be easily tuned. For building the workstation, we chose to use standard aluminium profiles and to use set squares in order to obtain easily adjustable parameters (work plan height and shelves height). Particular attention was paid on having a minimum number of parameters to set in the assembly of Computer-Aided Design (CAD) parts. Holed box specifications were precisely respected in order to obtain a high accuracy on hole shapes and contours.

\subsection{Manufacturing}

For the workstation, most of the parts comprising the structure were standard and only an assembly had to be performed. The holed box was composed of plexiglas plan and hole plans that were manufactured using Computer Numerical Controlled (CNC) machines. Files exported directly from the CAD model were used to manufacture these parts.

\subsection{Export to $3 D$ scene}

The VE simulation was defined to allow as natural as possible manipulation capabilities. The need of a 3D mesh model compatible with high visualization frame rates led to simplifying the mesh after the export. For haptic manipulations, a physics engine including contact management was mandatory. The visualization framework was based on OpenMask [17]. To obtain a visually realistic scene and enhance frame rate and performance of the soft, leaves and curved zones of the DMU were replaced by chamfers or chamfer combinations. The initial export was too heavy to be easily simulated, thus a simplification of shapes was performed, minimizing vertices on plans and filling in functional holes as they were not visible by subjects. 
Physics of the scene were simulated using the Bullet Physics Library ${ }^{1}$. As the Bullet library does not handle non-convex meshes properly, the DMU was modified to obtain only convex objects. The virtual holed box was modified to diminish the computational cost of physics simulation. Simplified holes were designed to keep their functionality (a hole can only let pass a unique fitter in a unique position and orientation), whereas visual aspect was unchanged as meshes of physics and rendering engines were dissociated.

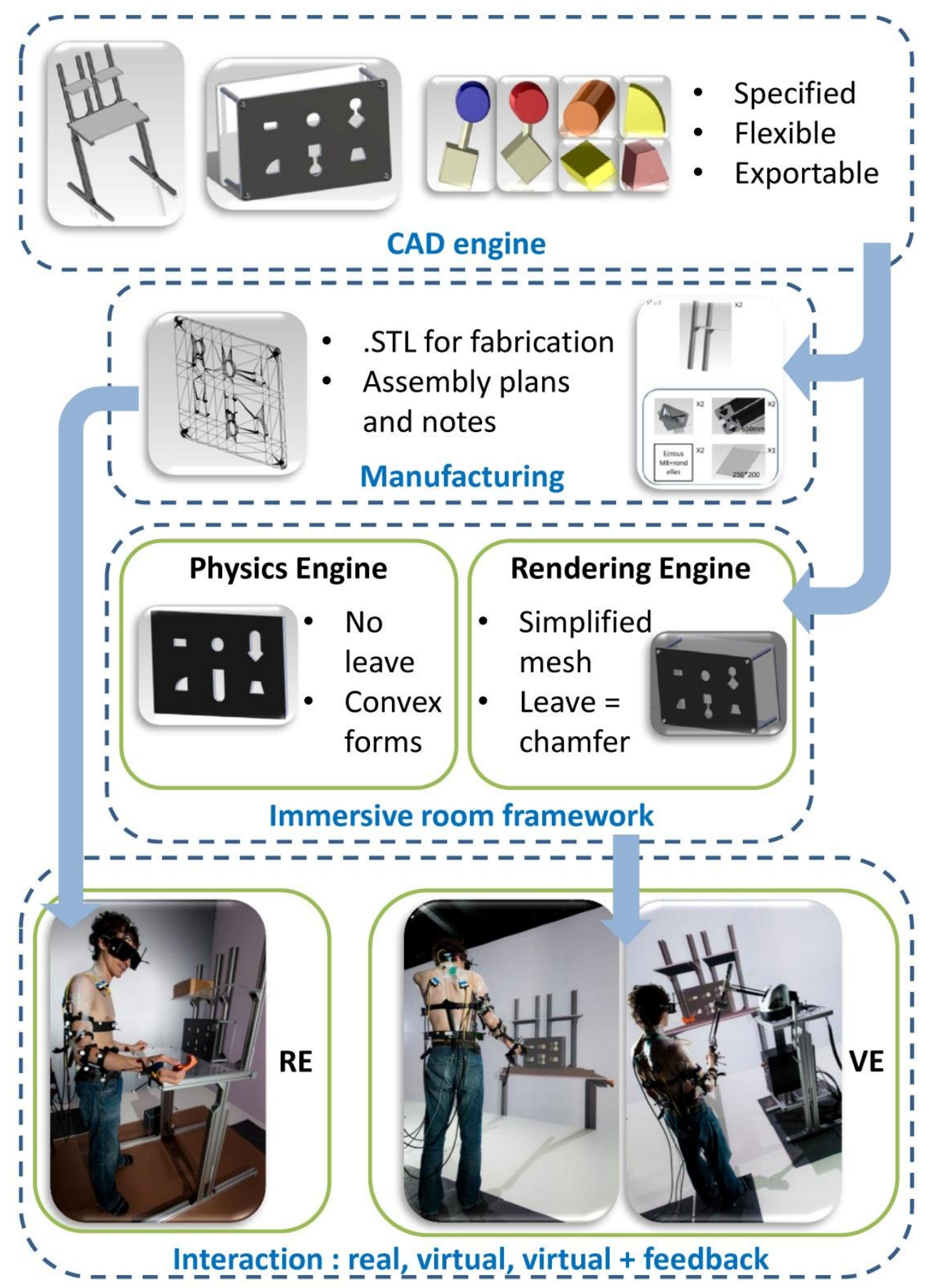

Fig. 2 Design pipeline from CAD model to fabrication and immersive room.

${ }^{1}$ www.bulletphysics.org

Pontonnier et al. 


\subsection{Implementation in Immersia}

Our team operates and maintains a Virtual Reality platform called IMMERSIA ${ }^{2}$. The equipment is a large immersive L-shape setup, which immerses the user in a high-quality visual and audible world. An overview of the room is shown in Fig. 3. The visual system uses eight Barco Galaxy NW12 projectors (BARCO Inc., USA) for the wall (resolution: $6240 \mathrm{x}$ 2016 pixels) and three Barco Galaxy 7+ projectors for the floor (resolution: $3500 \times 1050$ pixels). Stereoscopic images from Barco projectors are rendered on glass screens $(9.6 \mathrm{~m}$ large, $3 \mathrm{~m}$ height). A $360^{\circ}$ tracking system with 16 ART infra-red cameras (Advanced Real time Tracking GmbH, Germany) ${ }^{3}$ enables the localization of real objects within the L-shape. Sound rendering, not used in this experiment, is provided by a Yamaha processor, linked either to Genelec speakers with 10.2 format sound or Beyer Dynamic headsets with 5.1 virtual format sound, controlled by the user's position. Tracked 3D glasses (ActiveEyes-Pro, Volfoni, SAS, France) can adapt the simulation to the user point-of-view.

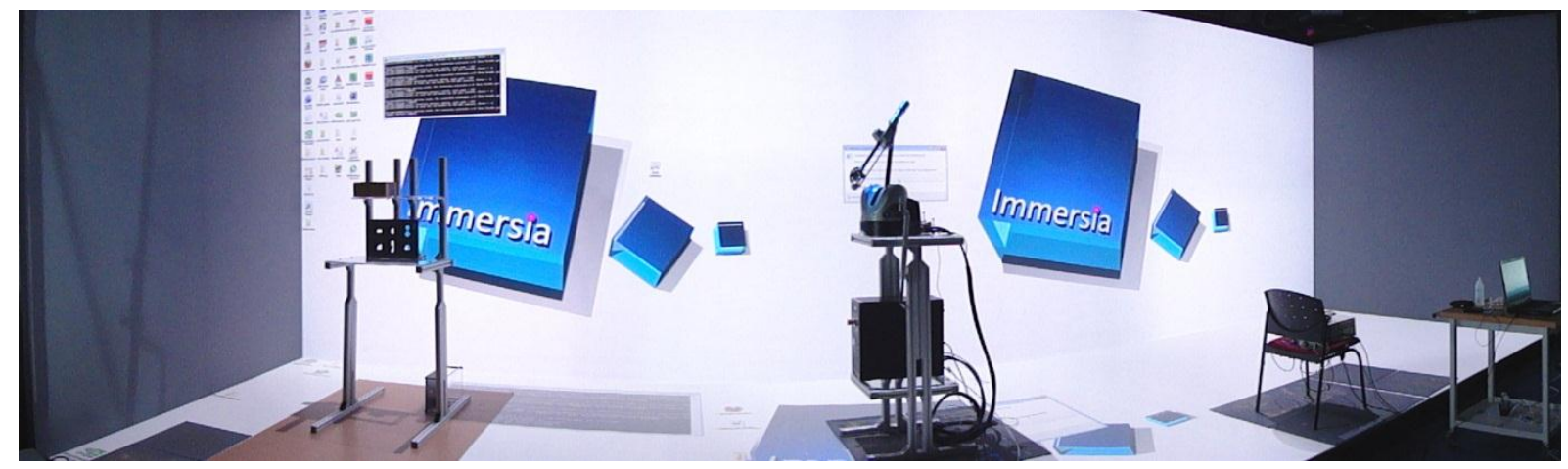

Fig. 3 Experimental setup in the immersive room overview. From left to right, real environment, virtual environment with force feedback, virtual environment without force feedback.

The experiment was set up using this VR system. The interaction was simulated with a Flystick2 (Advanced Real time Tracking GmbH, Germany) in the VE case and with a Virtuose $@ 6$ D haptic device (HAPTION SAS, Soulgé sur Ouette, France) ${ }^{4}$ in the VEF case. In the final study (currently being published [28]), motion of the upper body was tracked using the ART localization system and muscle activities were recorded using an EMG amplifier. The data obtained from these records is not discussed in the current article.

The room was physically divided in three zones of approximately 3 meters long in order to have the different environments (RE, VE and VEF) on a unique platform. Distributed architecture of software driving the room was based on a collaborative framework [11].

\section{Evaluation}

\subsection{Methods}

An initial evaluation of the fidelity of both VE and VEF with regard to RE was performed as a part of a more complete study not published yet. Ten subjects (age: $28.1 \pm 2.2 \mathrm{yrs}$; height: 179.9 $\pm 7.1 \mathrm{~cm}$; weight: $72.0 \pm 7.2 \mathrm{~kg}$, VR experience on a 5-point scale rated from "Novice" to

\footnotetext{
2 http://www.irisa.fr/immersia

3 http://www.ar-tracking.com

${ }^{4}$ http://www.haption.com
}

Pontonnier et al. 
"Expert": $1.7 \pm 0.9)$ performed two trials per environment. The complexity was set to "two holes", and both timing regime levels were tested ("as fast as possible", "time managed"). Environments were randomized to prevent task learning effect (balanced design). After each session in an environment, subjects answered a short questionnaire, rating several items. At the end of the experiment, they were invited to rate both VE and VEF in terms of environment fidelity and interaction fidelity. Paired Wilcoxon tests were processed on results to find significant differences between the environments.

\subsection{Results}

Results of the questionnaire are shown in table 1. Paired Wilcoxon tests raised the following points as significant results:

- The task was more difficult in VEF than in RE and VE;

- Under the "time managed" condition, subjects did have enough time to sort and place pieces in RE and VE, whereas they did not in VEF;

- Motion of subjects tended to be less natural in VE than in RE, in VEF than in RE and in VEF than in VE;

- Accessibility to the different zones was more difficult in VE than in RE, in VEF than in RE, and in VEF than in VE;

- Placing the fitters in the holes was more difficult in VE than in RE, in VEF than in RE and in VEF than in VE.

VE rating highlighted that VEF appeared globally less realistic than VE. Interaction appeared also less realistic in VEF than in VE.

\begin{tabular}{|c|c|c|c|c|c|c|c|c|c|}
\hline \multirow[b]{2}{*}{ Item } & \multicolumn{2}{|c|}{ RE } & \multicolumn{2}{|c|}{ VE } & \multicolumn{2}{|c|}{ VEF } & \multicolumn{3}{|c|}{ p-values } \\
\hline & Mean & $\mathrm{SD}$ & Mean & $\mathrm{SD}$ & Mean & SD & $\begin{array}{l}\text { RE vs } \\
\text { VE }\end{array}$ & $\begin{array}{l}\text { RE vs } \\
\text { VEF }\end{array}$ & $\begin{array}{l}\text { VE vs } \\
\text { VEF }\end{array}$ \\
\hline Was the task easy to perform? & 4.9 & 0.3 & 4.7 & 0.7 & 2.9 & 1.0 & $>0.05$ & $<0.05$ & $<0.05$ \\
\hline \multicolumn{10}{|l|}{ 1.Absolutely not/5. Absolutely } \\
\hline $\begin{array}{l}\text { Time Managed: enough time to } \\
\text { succeed? }\end{array}$ & 5 & 0 & 5 & 0 & 2 & 1.1 & $>0.05$ & $<0.05$ & $<0.05$ \\
\hline \multicolumn{10}{|l|}{ 1.Absolutely not/5. Absolutely } \\
\hline $\begin{array}{l}\text { Was it easy to differentiate } \\
\text { fitters and non-fitters? }\end{array}$ & 5 & 0 & 4.8 & 0.2 & 5 & 0 & $>0.05$ & $>0.05$ & $>0.05$ \\
\hline \multicolumn{10}{|l|}{ 1.Absolutely not/5. Absolutely } \\
\hline $\begin{array}{c}\text { Do you think your motion was } \\
\text { natural? }\end{array}$ & 4.5 & 0.5 & 3.8 & 0.9 & 2.4 & 1.1 & $<0.05$ & $<0.05$ & $<0.05$ \\
\hline \multicolumn{10}{|l|}{ 1.Absolutely not/5. Absolutely } \\
\hline $\begin{array}{l}\text { Was it difficult to access the } \\
\text { different zones of the } \\
\text { workstation? }\end{array}$ & 1.1 & 0.3 & 1.6 & 0.7 & 2.6 & 1.1 & $<0.05$ & $<0.05$ & $<0.05$ \\
\hline \multicolumn{10}{|l|}{ 1.Absolutely not/5. Absolutely } \\
\hline $\begin{array}{l}\text { Was it easy to pass the fitters } \\
\text { through the holes? }\end{array}$ & 4.9 & 0.3 & 4.0 & 1.1 & 3.0 & 1.5 & $<0.05$ & $<0.05$ & $<0.05$ \\
\hline \multicolumn{10}{|l|}{ 1.Absolutely not/5. Absolutely } \\
\hline & \multicolumn{4}{|c|}{ VE } & \multicolumn{4}{|c|}{ VEF } & \\
\hline VE Rating & \multicolumn{2}{|c|}{ Mean } & \multicolumn{2}{|c|}{ SD } & \multicolumn{2}{|c|}{ Mean } & \multicolumn{2}{|c|}{ SD } & p-value \\
\hline Environment fidelity & \multicolumn{2}{|c|}{3.8} & \multicolumn{2}{|c|}{0.8} & \multicolumn{2}{|c|}{3.1} & \multicolumn{2}{|c|}{1.2} & $<0.05$ \\
\hline \multicolumn{10}{|l|}{ 1.Unrealistic/5.Realistic } \\
\hline Interaction fidelity & \multicolumn{2}{|c|}{4.0} & \multicolumn{2}{|c|}{0.8} & \multicolumn{2}{|c|}{3.3} & \multirow{2}{*}{\multicolumn{2}{|c|}{1.4}} & $<0.05$ \\
\hline 1.Unrealistic/Realistic & & & & & & & & & \\
\hline
\end{tabular}

Table 1 Questionnaire results. Each item is evaluated on a 5-point scale. A p value below

0.05 was considered as significant.

Pontonnier et al. 


\subsection{Discussion}

Considering these results, VE and RE were closer in terms of subjective fidelity than VEF and RE. This observation is mostly due to the mechanical limitations of the haptic device. The subject had to reposition the handle relatively to the co-localized target in order to obtain complete rotation, necessary to place the fitters in the holes in some cases. In other terms, even if the workstation design was taking into account the work volume of the device, manipulation of pieces remained unnatural as additional gestures were necessary to complete the task.

It resulted in an increased difficulty, a less natural motion, a reduced accessibility and a longer duration of the task that would affect productivity in the long run. In VE, motion became less natural than in RE. Even if the interaction in VE was closer to the one in RE than in VEF, this result is of importance. Given that subjects were novices in VR (VR experience on a 5-point scale rated from "Novice" to "Expert": $1.7 \pm 0: 9)$, it could be due to an unfamiliarity of the subjects with the VE. Modulation of sensory feedback, in line with [35], induced an alteration of motor control. The interfaces used to interact with the virtual scene, as well as the scene itself, differed from the real situation. It induced that sensory feedback channels (mostly touch and view here) received altered signals that generated changes in the way the interaction was realized. This observation is in line with the fact that since cognition is affected by the environment, motor control is also altered [34]. This is also in accordance with the ACT-R theory [1], as altered cognition will lead to more effort and more muscle co-contraction to perform a task in an unfamiliar environment, due to an increased mental load and a longer process in the perception-action loop. It has also been noticed in [19] that familiarity of the environment has an impact on performance: the more familiar the environment is, the better is the performance. Unfamiliarity also resulted in a reduced accessibility and an increased difficulty to pass fitters through the holes, whereas no mechanical constraint was active in VE.

The rating of the environment confirms previous remarks about cognition. Even if the environment was visually and physically identical in VE and VEF, subjects perceived the environment as less realistic in VEF than in VE. Moreover the interaction was significantly perceived as less realistic in VEF than in VE. It indicates that despite of the addition of a physical sense to the scene via the force feedback, the mechanical limitations of the haptic device lowered the sensation of presence. Despite of these considerations, environment fidelity was rated at a reasonable level, confirming our design choices.

This evaluation requires further processing, and concerns only a part of the experimental protocol. It is necessary to conduct complete experiments on a larger population size, implying objective measures of discomfort and muscle fatigue, e.g. postural scores, kinematical traces or muscular activity, to highlight the differences between the various environments. Nevertheless, as a first result, it appears clear that the use of a co-localized haptic device asks for further improvements to be totally satisfying. It seems convenient and full of promises to use 6-DoF devices for such applications, and mixing sensor-sharing and sensor-bridging communication [3] could be a solution to bypass the mechanical limitations: one can imagine that translation and rotation in the virtual scene could be scaled differently to maximize the manipulability of the virtual objects while keeping the scale-1 feeling. Moreover, using other feedback channels, e.g. using sound to emulate force feedback, could be a way to enhance the user experience. Paradoxically such a sensor-bridging 
communication may be more effective in terms of fidelity than trying to directly replicate natural interaction. This is one of the rationales behind sensor-bridging communication, and cognitive infocommunication channels in general.

\section{Toward VR-based ergonomic design sessions}

In spite of the previous considerations and the multiple unsolved related challenges [31], one can imagine how such a simulator can be used in an industrial context. The first requirement to impose VR-based simulators as efficient ergonomics design tools in the industry is the cost. Even if one can easily imagine the numerous advantages of such tools, e.g. reactivity, gain of time, modularity,...it still has to be more cost-effective than fabricating a scale- 1 physical mock-up to evaluate ergonomic features of a workstation. It remains complicated to fulfil this requirement, as VR facilities are still relatively expensive. It implies that the initial investment has to be damped along time, requiring an intensive and systematic use as an ergonomic design tool. This is one reason pushing front side the issue of the numerical chain, that has been partially addressed in the current article. The numerical chain has to be standardized and straightforward to be used easily, without additional treatment going from one platform (CAD) to one other (fabrication, VE).

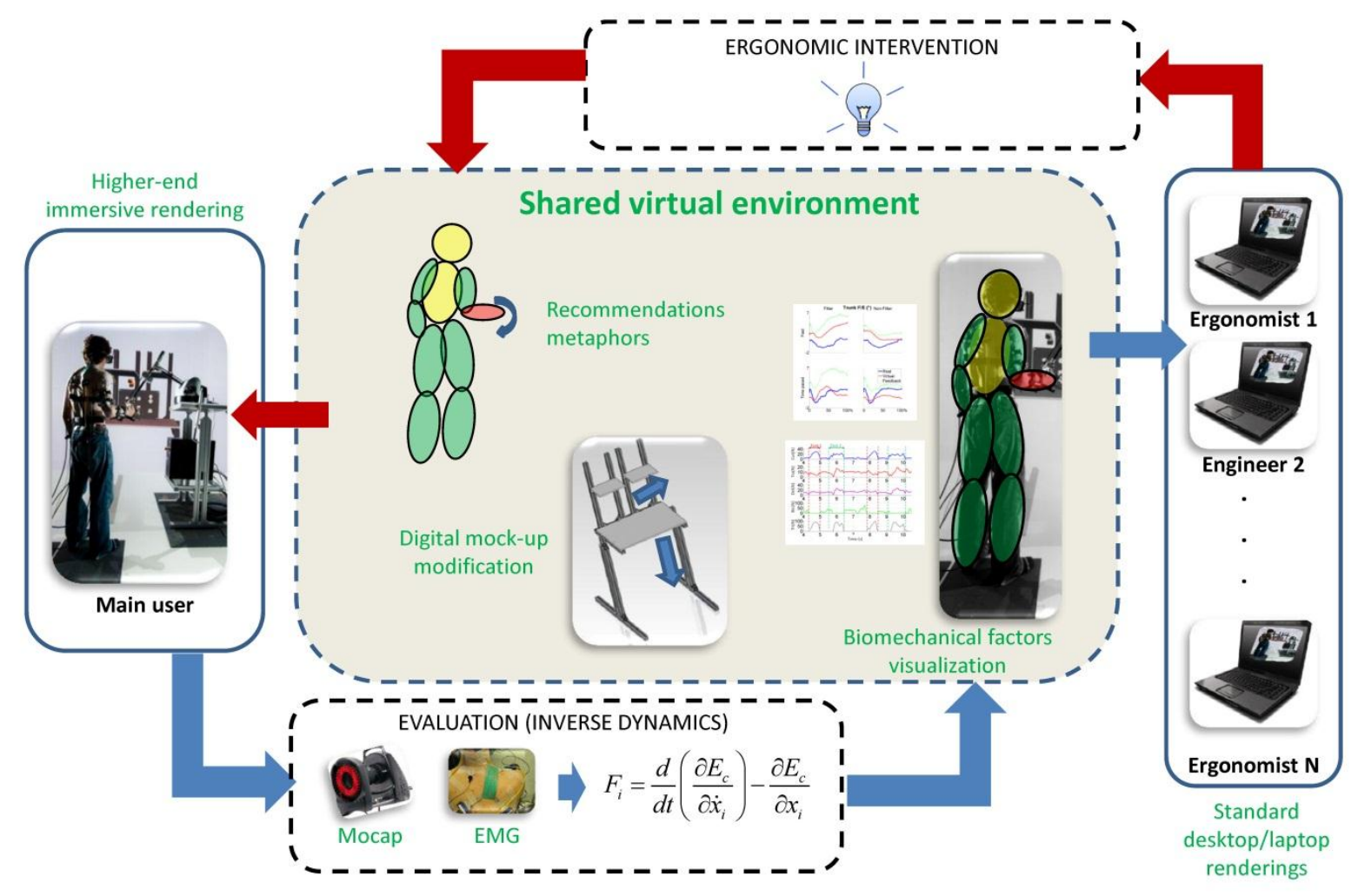

Fig. 4 Collaborative framework for VR-based ergonomic design sessions.

An additional argument to adopt such tools is the promising possibility to animate remote ergonomic design sessions by sharing the same virtual environment. Indeed, we plan to use a collaborative framework $[9,11]$ and share it among the actors of product and workstation design to perform an evaluation. The idea, as shown in Fig. 4, is to compute and visualize under several representations the biomechanical risk factors involved in the musculoskeletal disorders appearance at work (e.g. posture scores, kinematic features, muscle forces,...) [27]. To do so, the worker (main user) is immersed in a virtual representation of the workstation

Pontonnier et al. 
such as the one presented in the current article, and he/she and the collaborators (ergonomists, engineers) are visualizing in real-time biomechanical factors during the realization of work tasks. Biomechanical factors could be represented either on a virtual manikin, enhancing the main user proprioception [20] or as simple scores and curves for the ergonomists. Ergonomists can then interactively advise the main user to enhance the way he/she is performing the task (more comfortable postures, less awkward motions). Design engineers can on their side modify the work environment in relation with ergonomists' and users' advices (features position, work cycle organization,...). This intervention should be done with respect to the functionalities and specifications of the workstation in terms of productivity and quality. Some metaphors that could, for example, be inspired from the guiding techniques presented in [22] should be designed and tested for such purpose. A specific work on sensorbridging and sensor-sharing information has to be done here to enhance user's cognition and comprehension of the task and the recommendations proposed by the remote users. For example, one can think that ergonomic recommendation, such as lowering the arm in a given posture, can be proposed by an ergonomist in animating a ghost avatar whereas it will be shown to the main user as a metaphoric arrow indicating the direction of lowering on the current avatar, on which the region of interest (the arm) should be highlighted.

The strength of the framework proposed here is the adaptation to very different user interfaces, from higher end rendering systems with haptic interfaces to standard laptop rendering systems [9]. It enables a very flexible use, especially interesting with regard to the arguments previously developed about the cost of VR-based ergonomic design evaluations. The framework could be extended in the future to several other activities, such as coaching, training or rehabilitation.

\section{Conclusion and Perspectives}

In this article, the definition and evaluation of a DMU in real and virtual environment has been presented. A particular attention has been paid to define guidelines to realize a real mock-up and export a virtual one from a unique initial digital mock-up. Simulated assembly tasks performed on the designed workstation were compared in real (RE), virtual (VE) and virtual with force feedback (VEF) environments. With regard to this evaluation, advices and recommendations were provided for further experiments of such type. An initial evaluation of virtual environments fidelity in relation to the real one was performed.

Results of the evaluation highlight the importance of familiarity as a factor of cognition alteration. An increase in the difficulty was reported in VEF with regard to VE and RE. This point calls for improvements in the control and the design of haptic devices and interfaces to enhance their applicability in scale-1, colocalized simulations. To bypass mechanical limitations in such applications, a solution could be to dissociate translation and rotation scales between the real and the virtual world. Moreover, as distortion between physical and visual perception of the scene is a way to enhance fidelity, future work can focus on this aspect for the design of workstation DMUs, enabling a direct evaluation in a virtual environment for ergonomics purposes. Improving the fidelity and the usability of such simulators in defining a straightforward numerical chain is a keypoint for generalizing the use of VR-based ergonomic design sessions. As it has been explained in the last section of this article, the use of such simulators in a collaborative framework promises numerous efficient applications. 


\section{Acknowledgment}

We wish to thank Quentin Avril, Thierry Duval and Bruno Arnaldi, IRISA researchers for their kind support. We also wish to thank Jérome Quesné, Benjamin Lollivier and Mazyar Yosofi, undergraduate students, for their active participation. This work was supported by the European Project VISIONAIR ${ }^{5}$ [16] (VISIONAIR is under grant agreement 262044) and the Danish Council for Independent Research | Technology and Production Sciences (FTP). Grant number: 10092821.

\section{References}

1. Anderson, J., Bothell, D., Byrne, M., Douglass, S., Lebiere, C., Qin, Y.: An integrated theory of the mind. Psychological review 111(4), 1036 (2004)

2. Backstrand, G., Hogberg, D., Vin, L.J.D., Case, K., Piamonte, P.: Ergonomics analysis in a virtual environment. International Journal of Manufacturing Research 2, 198-208 (2007)

3. Baranyi, P., Csapo, A.: Cognitive infocommunications: Coginfocom. In: Computational Intelligence and Informatics (CINTI), 2010 11th International Symposium on, pp. 141-146. IEEE (2010)

4. Boothroyd, G., Dewhurst, P.: Product design for assembly. McGraw-Hill, New York (1989)

5. Bordegoni, M., Cugini, U., Belluco, P., Aliverti, M.: Evaluation of a haptic-based interaction system for virtual manual assembly. In: Proceedings of the 3rd International Conference on Virtual and Mixed Reality, pp. 303-312. Springer-Verlag, Berlin, Heidelberg (2009)

6. Brough, J.E., Schwartz, M., Gupta, S.K., Anand, D.K., Kavetsky, R., Pettersen, R.: Towards the development of a virtual environment-based training system for mechanical assembly operations. Virtual Reality 11, 189-206 (2007)

7. Dai, F., Felger, W., Frühauf, T., Göbel, M., Reiners, D., Zachmann, G.: Virtual prototyping examples for automotive industries. In: Virtual Reality World (1996)

8. Du, J., Duffy, V.: A methodology for assessing industrial workstations using optical motion capture integrated with digital human models. Occupational Ergonomics 7, 11-25 (2007)

9. Duval, T., Nguyen, H., Fleury, C., Chauffaut, A., Dumont, G., Gouranton, V.: Embedding the features of the users' physical environments to improve the feeling of presence in collaborative virtual environments. In: Cognitive Infocommunications (CogInfoCom), 2012 IEEE $3^{\text {rd }}$ International Conference on, pp. 243-248. IEEE (2012)

10. Eurofound: Change over time - first findings from the fifth european working conditions survey. European Foundation for the Improvement of Living and Working Conditions

(2010)

11. Fleury, C., Chauffaut, A., Duval, T., Gouranton, V., Arnaldi, B.: A generic model for embedding users' physical workspaces into multi-scale collaborative virtual environments. "ICAT 2010 (20th International Conference on Artificial Reality and Telexistence)" (2010)

12. Gerathewohl, S.J.: Fidelity of simulation and transfer of training: a review of the problem. Department of Transportation, Federal Aviation Administration, Office of Aviation Medicine (1969)

13. Holt, P.O., Ritchie, J.M., Day, P.N., Simmons, J.E.L., Robinson, G., Russell, G.T., Ng, F.M.: Immersive virtual reality in cable and pipe routing:design metaphors and cognitive ergonomics. Journal of Computing and Information Science in Engineering 4(3), 161-170 (2004)

\footnotetext{
${ }^{5}$ http://www.infra-visionair.eu
}

Pontonnier et al. 
14. Jayaram, U., Jayaram, S., Shaikh, I., Kim, Y., Palmer, C.: Introducing quantitative analysis methods into virtual environments for real-time and continuous ergonomic evaluations. Computers in Industry 57(3), 283 - 296 (2006)

15. Kobe, G.: Virtual interiors. Automotive Industries 175(5), 52-54 (1995)

16. Kopecki, A., Wössner, U., Mavrikios, D., Rentzos, L., Weidig, C., Roucoules, L., Ntofon, O.D., Reed, M., Dumont, G., Bündgens, D., Milecki, A., Baranyi, P., Noel, F., Masclet, C., Attene, M., Giannini, F., Spagnuolo, M.: VISIONAIR: VISION Advanced Infrastructure for Research. SBC Journal on 3D Interactive Systems 2(2), 40-43 (2011)

17. Larrodé, X., Chanclou, B., Aguerreche, L., Arnaldi, B.: Openmask: an open-source platform for virtual reality. In: Software Engineering and Architectures for Realtime Interactive Systems (SEARIS) (2008)

18. McCormik, E.J., Sanders, M.S.: Human Factors in engineering and design (1987)

19. McMahan, R., Bowman, D., Zielinski, D., Brady, R.: Evaluating display fidelity and interaction fidelity in a virtual reality game. Visualization and Computer Graphics, IEEE Transactions on 18(4), 626-633 (2012).

20. Mine, M.R., Brooks Jr, F.P., Sequin, C.H.: Moving objects in space: exploiting proprioception in virtual environment interaction. In: Proceedings of the 24th annual conference on Computer graphics and interactive techniques, pp. 19-26. ACM Press/Addison-Wesley Publishing Co. (1997)

21. Müller, M., Dorsey, J., McMillan, L., Jagnow, R., Cutler, B.: Stable real-time deformations. In: Proceedings of the 2002 ACM SIGGRAPH/Eurographics symposium on Computer animation, pp. 49-54. ACM (2002)

22. Nguyen, T.T.H., Fleury, C., Duval, T.: Collaborative exploration in a multi-scale shared virtual environment. In: 3D User Interfaces (3DUI), 2012 IEEE Symposium on, pp. 181-182. IEEE (2012)

23. Pappas, M., Karabatsou, V., Mavrikios, D., Chryssolouris, G.: Ergonomic evaluation of virtual assembly tasks. In: Digital Enterprise Technology, pp. 511-518 (2007)

24. Picon, F.: Interaction haptique pour la conception de formes en CAO immersive. Ph.D. thesis, Université Paris XI (2010)

25. Pontonnier, C., Dumont, G.: Inverse Dynamics Method using Optimisation Techniques for the Estimation of Muscle Forces Involved in the Elbow Motion. International Journal on Interactive Design and Manufacturing (IJIDeM) 3, 227-235 (2009)

26. Pontonnier, C., Dumont, G.: Motion Analysis of the Arm based on Functional Anatomy. In: Springer (ed.) 3D Physiological Human 2009, Lecture Notes in Computer Sciences 5903 (2009)

27. Pontonnier, C., Dumont, G.: From Motion Capture to Muscle Forces in the Human Elbow Aimed at Improving the Ergonomics of Workstations. Virtual and Physical Prototyping 5, 113-122 (2010)

28. Pontonnier, C., Samani, A., Badawi, M., Madeleine, P., Dumont, G.: Assessing the ability of a vr-based assembly task simulation to evaluate physical risk factors. IEEE Transactions on Visualization and Computer Graphics In press (2013)

29. Pontonnier, C., de Zee, M., Samani, A., Dumont, G., Madeleine, P.: Meat Cutting Tasks Analysis using 3D Instrumented Knife and Motion Capture. In: 15th Nordic- Baltic Conference on Biomedical Engineering and Medical Physics, IFMBE Proceedings, vol. 34, pp. 144-147 (2011)

30. Pontonnier, C., de Zee, M., Samani, A., Dumont, G., Madeleine, P.: Cutting force and emg recordings for ergonomics assessment of meat cutting tasks : influence of the workbench height and the cutting direction on muscle activation levels. In: ASME 2012 11th Biennial Conference On Engineering Systems Design And Analysis (ESDA) (2012) 
31. Rebelo, F., Noriega, P., Duarte, E., Soares, M.: Using virtual reality to assess user experience. Human Factors: The Journal of the Human Factors and Ergonomics Society 54(6), 964-982 (2012)

32. Schmitz, B.: Great expectations-the future of virtual design. Computer-Aided Engineering 14(10), 68 (1995)

33. Seth, A., Su, H.J., Vance, J.M.: Sharp: A system for haptic assembly and realistic prototyping. In: ASME 2006 International Design Engineering Technical Conferences and Computers and Information in Engineering Conference (2006)

34. Stoffregen, T., Bardy, B.G., Smart, L., Pagulayan, R.: Virtual and adaptive environments : Applications, implications, and Human performance issues, chap. "On the nature and evaluation of fidelity in virtual environments", pp. 111-128 (2003)

35. Svendsen, J., Samani, A., Mayntzhusen, K., Madeleine, P.: Muscle synergies and force variability during precision and tracking tasks. Human Movement Science 30, 1039- 1051 (2011)

36. Tching, L., Dumont, G., Perret, J.: Interactive simulation of cad models assemblies using virtual constraint guidance. International Journal on Interactive Design and Manufacturing (IJIDeM) 4(2), 95-102 (2010)

37. Vo, D.M., Vance, J.M., Marasinghe, M.G.: Assessment of haptics-based interaction for assembly tasks in virtual reality. World Haptics Conference pp. 494-499 (2009)

38. Volkov, S., Vance, J.M.: Effectiveness of haptic sensation for the evaluation of virtual prototypes. ASME Journal of Computing and Information Sciences in Engineering 1(2), 123 $128(2001)$

39. Wall, S., Harwin, W.: Quantification of the effects of haptic feedback during a motor skills task in a simulated environment. In: Proceedings of Phantom User Research Symposium'00 (2000)

40. Wang, Z., Dumont, G.: Interactive two-stage rendering technique of deformable part through haptic interface. ASME Conference Proceedings 2011(44328), 133-143 (2011)

41. Whitman, L.E., Jorgensen, M., Hathiyari, K., Malzahn, D.: Virtual reality: its usefulness for ergonomic analysis. In: Proceedings of the 36th conference on Winter simulation, pp. 1740-1745. Winter Simulation Conference (2004) 